\title{
PRODUÇÃO COLABORATIVA DE TEXTOS MULTIMODAIS A PARTIR DO GÊNERO INFOGRÁFICO DIGITAL
}

\author{
Elizabeth Mota Nazareth de Almeida * \\ Girlene Lima Portela *
}

Resumo: O presente artigo visa apresentar os resultados obtidos a partir da pesquisa intervenção desenvolvida no âmbito do PROFLETRAS/UEFS. A pesquisa teve o objetivo de desenvolver ações didático-pedagógicas voltadas para a escrita colaborativa de infográficos digitais, aliando o uso das TDIC ao ensino-aprendizado em Língua Portuguesa, com vistas à ampliação das competências escritoras de estudantes do Tempo Formativo Juvenil 04, do turno noturno de uma escola da Rede Estadual do município de Feira de Santana, Bahia. A pesquisa intervenção desenvolvida encontra-se inserida no campo das pesquisas de natureza aplicada, onde desenvolvemos sequências didáticas voltadas para práticas de leitura e escrita de textos multimodais, a partir do gênero textual infográfico, com o apoio de uma plataforma online, intitulada Portal Cibernautas, e de um Caderno de Atividades, ambos criados pela professora-pesquisadora. Percebemos, a partir dos dados obtidos neste estudo, avanços na competência escritora, autonomia, colaboração, criatividade e criticidade dos sujeitos. Palavras-chave: Infográfico. Multimodalidade. Hipertexto. Multiletramentos.

Introdução

Com o advento da internet, a leitura/escrita hipermidiática encontra-se cada vez mais presente em nosso cotidiano, e assim, em nossa prática pedagógica, nos confrontamos com o desafio de conduzirmos o estudante para experiências leitoras e escritoras a partir desse contexto multimodal e tecnológico digital, oportunizando o desenvolvimento de indivíduos autônomos, colaborativos e críticos. Para isso, entretanto, devemos refletir a respeito dos usos que as novas tecnologias podem proporcionar em prol da construção do conhecimento e de uma visão empoderada, evitando os extremos de sua supervalorização ou exclusão. A chave é acharmos o ponto de equilíbrio para que, através das práticas de multiletramentos (independente do suporte utilizado), possamos agir na sociedade de maneira crítica e colaborativa.

Diante dessa realidade, vimos a necessidade de desenvolver ações direcionadas para práticas leitoras e escritoras de textos multimodais na escola que aliem o uso das Tecnologias Digitais de Informação e Comunicação (TDIC) ao ensino de Língua Portuguesa. Tendo em mente, entretanto, que a simples apropriação de novas tecnologias não é capaz, por si só, de reverter situações educacionais (PRETTO; PINTO, 2006, p. 23), propomos o reposicionamento de papeis no processo de ensino-

\footnotetext{
*Mestra em Letras, pelo PROFLESTRAS/UEFS. Especialista em Psicopedagogia pela Universidade Castelo Branco/RJ. Licenciada em Letras dupla habilitação Português/Inglês pela UEFS. Professora da rede estadual de ensino, Bahia. lizzymotadealmeida@gmail.com

*Professora Orientadora PROFLETRAS/UEFS. Doutora e PhD em Educação pela Université de Sherbrooke (2003). Professora Plena da Universidade Estadual de Feira de Santana (UEFS). falecom@girleneportela.com.br
} 
aprendizagem. Devemos assumir uma postura onde se privilegie o estudante como protagonista na construção do seu conhecimento, utilizando-se, para isso, das novas tecnologias digitais como forma de multiplicar as oportunidades desses aprendizes de "lidarem com o mar de informações disponível na grande rede, a fim, de bem utilizadas, aplicarem-nas em sua formação de maneira interativa e multidimensional" (XAVIER, 2007, p. 5).

Baseados nesse contexto, desenvolvemos a pesquisa, intitulada Portal Cibernautas: Produção de textos multimodais a partir do gênero infográfico digital, inserida no âmbito do Programa de Mestrado Profissional em Letras (PROFLETRAS/UEFS), do Departamento de Letras e Artes da Universidade Estadual de Feira de Santana, vinculada à Linha de Pesquisa II - Leitura e Produção Textual: diversidade social e práticas docentes.

A partir das experiências vivenciadas pela pesquisadora, sobretudo na Escola Básica da Rede Pública Estadual, no que diz respeito às dificuldades de aprendizagem apresentadas pelos alunos em sala de aula de Língua Portuguesa e uso das TDIC em sala de aula, surgiram questionamentos e inquietações que posteriormente foram levados ao PROFLETRAS sob forma de proposta de intervenção. Algumas destas inquietações dizem respeito à seguinte questão: Quais saberes necessários voltados para a competência escritora podem ser construídos a partir do desenvolvimento de sequências didáticas voltadas para práticas de leitura e escrita de textos multimodais com foco na produção colaborativa de infográficos digitais nas aulas de Língua Portuguesa?

Para responder a esta questão, nos debruçamos sobre nosso objeto, a saber, as produções textuais de infográficos digitais construídos colaborativamente por estudantes da turma do Tempo Formativo Juvenil 04 (8\%/9o ano do Ensino Fundamental II), do turno noturno de uma escola pública da Rede Estadual, localizada no município de Feira de Santana, Bahia.

O Tempo Formativo Juvenil faz parte de uma proposta educacional para a educação básica, nível fundamental, apresentada pela Secretaria de Educação do Estado da Bahia como uma referência para a efetivação de uma política própria para o atendimento dos estudantes adolescentes de 15 (quinze) a 17 (dezessete) anos em defasagem idade/série.

A fim de respondermos a questão de pesquisa e darmos conta do nosso objeto de estudo, estabelecemos como objetivo principal desenvolver ações didático-pedagógicas voltadas para a prática de leitura/escrita de textos multimodais com foco na produção colaborativa de infográficos digitais, pensadas para contribuir com a ampliação da competência escritora dos estudantes, aliando desta forma a aprendizagem da Língua Portuguesa ao uso das Tecnologias Digitais de Informação e Comunicação. 
Para alcançar o objetivo acima, foram estabelecidos objetivos específicos, a saber, desenvolver sequências didáticas voltadas para práticas leitoras e escritoras a partir do gênero infográfico; conhecer as dificuldades e estratégias apresentadas pelos estudantes quando expostos a uma situação real de produção textual colaborativa de infográficos digitais; avaliar os saberes necessários construídos a partir da escrita de gêneros multimodais em Língua Portuguesa; e, por fim, promover debates, a partir da reflexão/ação, acerca do uso didático de gêneros multimodais na escola.

A escolha do infográfico se deu por se tratar de um gênero multimodal, que agrega, em um único texto, a linguagem verbal e não verbal, apresentando características interativas e hipertextuais quando construído para a web, possuindo assim o potencial para produção de sentido, unindo sons, músicas, vídeos, imagens etc. Desta forma, ao propormos a produção do gênero infográfico, podemos proporcionar ao estudante a ampliação da capacidade complexa de relacionar entre si informações verbais e não verbais encontradas em textos multissemióticos (COSCARELLI, 2016, p. 44 - 45).

É importante enfatizar, entretanto, que nosso intuito não foi exigir que os alunos produzissem materiais profissionais, semelhantemente aos publicados em revistas e jornais reconhecidos, mas antes, desenvolver e ampliar as suas competências escritoras em consonância com que é esperado para a série em que estão inseridos, capacitando-os a produzirem outros gêneros textuais segundo a sua necessidade comunicativa.

Levamos em consideração ainda, para avaliarmos o nível dos conhecimentos construídos pelos estudantes ao longo da proposta de intervenção, os saberes necessários (SN) em Língua Portuguesa, a partir do que é esperado para o Tempo Formativo Juvenil, de acordo com que preconizam os Cadernos Didáticos do Percurso de Aprendizagem para o Tempo Formativo Juvenil (BAHIA/SEC/CEJA, 2010), a saber, se o estudante, ao final dos processos de produção inicial e final dos infográficos digitais: elabora paráfrases dos textos lidos (SN01); seleciona textos para leitura individual e coletiva (SN02); compreende e interpreta textos lidos, selecionando dados e informações (SNO3); organiza, com maior visibilidade, a estrutura do texto escrito em função das características do gênero (SN04); e, realiza a reescrita de textos sem perder de vista as ideias originais (SN05).

\section{Pressupostos teóricos}

\subsection{As TDIC na escola e as práticas de multiletramentos}

No final das décadas de 70 e 80 , com a propagação da microinformática e o advento da internet, adotou-se algumas expressões no sentido de sintetizar os fenômenos que então floresciam,

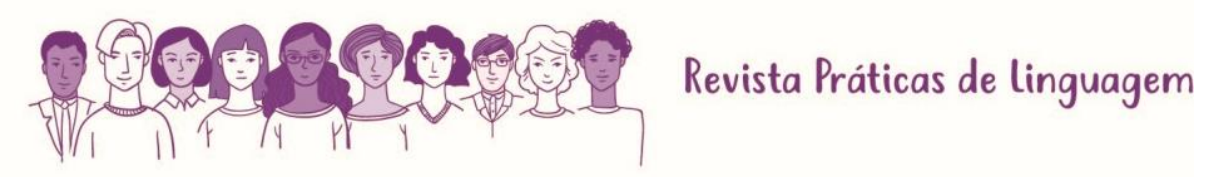


como TIC (Tecnologias de Informação e Comunicação), Era da Informação ou Digital e Cibercultura (LÉVY, 1999). Para Afonso (2002) a sigla TIC, a rigor, deveria ser TDIC (Tecnologias Digitais de Informação e Comunicação), uma vez que "tecnologias de informação e comunicação existem desde tempos imemoriais, mas suas formas digitais são um fenômeno que se consolidou na última década do século XX" (AFONSO, 2002, p. 169).

De fato, ao olharmos o panorama educacional brasileiro no que tange à difusão das TDIC nas escolas, facilmente percebemos que as instituições estão sendo gradativamente equipadas e instrumentalizadas. Entretanto, é perceptível também que muitas vezes utilizamos algumas ferramentas tecnológicas digitais com a mesma antiga metodologia de aula magistral, onde o professor fala e o aluno ouve e reproduz o que ouviu. Assim, observamos que ainda há uma lacuna a ser preenchida para a inclusão efetiva das TDIC nas práticas escolares no Brasil, visto que, o simples fato de se equipar um laboratório de informática ou usar um data show em uma aula não garante um ensino transformado pelas novas tecnologias ou práticas de multiletramentos.

Para que isso ocorra, se faz necessário o reposicionamento de papeis no processo de ensinoaprendizagem, onde se privilegie o estudante como protagonista na construção do seu conhecimento, a partir de uma proposta colaborativa de aprendizagem, levando-se em consideração à relação dessas novas tecnologias com as práticas efetivas em sala de aula, em prol de uma aprendizagem significativa, valorizando-se "a multiplicidade cultural das populações e a multiplicidade semiótica de constituição dos textos por meio dos quais ela se informa e se comunica" (ROJO, 2012, p. 13).

Direcionando nosso olhar para as práticas de leitura e escrita no ciberespaço, percebemos que, cotidianamente, nos deparamos com a linguagem através de suas multiformas e multissemioses, repletas de signos, sons, ícones, imagens e organizados como hipertextos digitais. Sabendo-se que é o próprio navegador do ciberespaço quem possui o leme que define as direções a serem seguidas nestas leituras hipermidiáticas, percebemos que se faz necessário uma maior atenção às questões relacionadas à forma como o estudante, nativo digital, lida com o oceano hipermidiático, diverso e multicultural, e, principalmente, de que maneira ele conduz essas informações para a construção da sua identidade, conhecimento e uso da língua.

Entretanto, o desafio imposto pelas novas linguagens não são as suas características multissemióticas, multimodais ou hipermidiáticas, mas antes as práticas escolares de leitura/escrita que já eram restritas e insuficientes mesmo para a era do impresso. Os textos contemporâneos apresentam facilidades por permitir uma maior autonomia do leitor-escritor, ao criar suas próprias hipermídias, seus próprios hipertextos. São exatamente esses textos contemporâneos, compostos de muitas linguagens, que têm sido chamados de multimodais ou multissemióticos e que, muitas vezes 
apresentam um "caráter não multi, mas hiper: hipertextos, hipermídias" (ROJO, 2012, p. 21), que exigem novas ferramentas de produção, de análise crítica, enfim, exigem multiletramentos.

E é diante das novas exigências e aspectos apresentados na sociedade do século XXI, que buscamos os possíveis caminhos didático-pedagógicos que aliem as TDIC ao ensino-aprendizado em Língua Portuguesa.

Tendo esses aspectos como norteadores, lançamos a proposta de produção colaborativa de infográficos digitais, a partir da leitura de textos multimodais disponíveis na web, voltadas para ações didático-pedagógicas que visassem apresentar ao estudante gêneros textuais a partir de veículos de circulação da sociedade, como mote para uma escrita planejada e efetivamente significativa. Desta forma, oportunizamos ao estudante buscar as informações necessárias para a construção do seu conhecimento, realizando para isso, práticas de leituras de textos diversos, balizadas no que se refere à pedagogia dos multiletramentos.

\subsection{Afinal, o que é um infográfico}

O termo infográfico vem da redução das palavras anglo-saxônicas infomation e graphics e significa a representação gráfica de informação. Para isso, o infográfico utiliza "ferramentas visuais como mapas, desenhos, ilustrações e tabelas combinadas com texto, com a intenção de transmitir ao leitor informação complexa de um modo tal que torne fácil a compreensão" (NEVES, 2013, p. 12).

Sua utilização sistemática mundial, entretanto, expandiu-se apenas a partir da década de 80 , de forma gradual e constante, exatamente por conta das facilidades que a informática e o avanço de recursos de impressão introduziram no processo de produção do gênero (TEIXEIRA, 2010, p. 20). Contudo, com a expansão do ciberespaço, o infográfico ganhou novo status. Surgida em meados dos anos 1998, o infográfico digital agregou “a combinação entre o desenho, a ilustração e o jornalismo no meio online", possibilitando "relatar acontecimentos com o apoio de elementos visuais" (NEVES, 2013, p. 42), apropriando-se, desta forma, da linguagem verbal e não verbal, oportunizando ainda, a interatividade do leitor. Sobre isso, Costa (2014) traz a seguinte definição:

Infográficos são quadros informativos que misturam texto e ilustração para transmitir uma informação visualmente. [...] São representações visuais de informação. [...] É um recurso muitas vezes complexo, podendo se utilizar da combinação de fotografia, desenho e texto. [...] Em outras palavras, trata-se de uma criação gráfica que se utiliza de recursos visuais, conjugados a textos curtos, com o objetivo de divulgar informações jornalísticas, sucinta e atraentemente, em jornalismo impresso, tele e webjornalismo (COSTA, 2014, p. 148). 
Ainda segundo Costa (2014), o infográfico possui a característica de apresentar a notícia com detalhes mais relevantes e com forte apelo visual, facilitando a compreensão do texto e oferecendo uma percepção mais rápida e clara dos sujeitos, do tempo e do espaço da notícia, além de descrever fatos que o texto ou a foto, sozinhos, podem não conseguir detalhar com a mesma eficiência. Para Dionísio (2006, p. 139) o infográfico é uma das mais sofisticadas formas de "explicar complexas histórias ou procedimentos, por que combina palavras com imagens, quando palavras apenas poderiam ser cansativas para leitores e a imagem apenas seria insuficiente".

Pensando nestas características facilitadoras, enxergamos o infográfico como um gênero eficiente para guiar nossos alunos-leitores às leituras posteriores mais complexas, uma vez que o gênero exige a leitura simultânea de imagens e palavras, podendo ser feita de diversas maneiras, "(a) Pode-se ler texto como um todo, isto é, o texto verbal principal + o infográfico. (b) Pode-se ler apenas o texto verbal principal e olhar as imagens. (c) Pode-se ler apenas o infográfico, que possui seu próprio título e subtítulo" (DIONíSIO, 2006, p. 139).

Sendo um eficiente meio para sintetizarmos as informações, o infográfico seria "um texto multimodal por excelência, já que seu planejamento já o constrói com, pelo menos, palavras e imagens em um leiaute (na web, é possível agregar som, movimento etc.)" (RIBEIRO, 2016, p. 31), além de ser "um gênero que circula amplamente em jornais e revistas impressos, digitais e mesmo TV, nas previsões do tempo, nas explicações e nas demonstrações de fatos, causas, efeitos, trajetórias etc." (RIBEIRO, 2016, p. 31). Acrescentamos ainda, que uma vez que o infográfico digital, por suas características interativas e hipertextuais, possui o potencial para ligar em um único texto, sons, músicas, vídeos, imagens etc., podemos, desta forma, reconhecê-lo como um texto também hipermidiático por excelência.

Contudo, para ser um infográfico é necessário que haja unidade de significado, exigindo do seu leitor, para a sua compreensão, o relacionamento de informações em suas multilinguagens, para a produção de sentido.

Desta forma, vemos o infográfico como um gênero textual independente construído na multimodalidade, concebido por diferentes modos semióticos, que trazem, em uma mesma composição, informações verbais e não verbais, como imagens, sons, animações, vídeos, hiperlinks, entre outros, desde que seja possível atribuir um sentido a ele. Assim, a leitura/escrita de infográficos no ciberespaço teria o potencial de desenvolver competências consideradas como imprescindíveis, inclusive para leitura de "diferentes outros textos visuais informativos encontrados sobremaneira no cotidiano dos leitores na contemporaneidade, publicados em sites, portais, aplicativos, revistas e jornais" (COSCARELLI, 2016, p. 46). 
Apoiados nestes conceitos, apresentamos a situação comunicativa e o Módulo de Reconhecimento do Gênero a partir de atividades voltadas para leitura de infográficos publicados e postados por sites e revistas de circulação nacional.

\section{Metodologia}

Definimos o nosso percurso metodológico no campo das pesquisas aplicadas e da pesquisaintervenção, ao assemelhar-se, como esclarece Tripp (2005), à pesquisa-ação, ao que se refere ao tipo de pesquisa "feita pelo prático, adaptada às exigências (formais) de trabalhos acadêmicos" (TRIPP, 2005, p. 463). A pesquisa-intervenção, desta forma, compreende uma tendência das pesquisas participativas, que busca investigar a vida de coletividades na sua diversidade qualitativa, assumindo uma intervenção de caráter socioanalítico.

Situamos, desta forma, nossa pesquisa como intervenção no sentido trazido por Damiani (2012, p. 03) de promover "interferências (mudanças, inovações), propositadamente realizadas, por professores/pesquisadores, em suas práticas pedagógicas". Estas interferências foram ações planejadas e implementadas com base em um referencial teórico, objetivando promover avanços, melhorias, correlacionando a teoria com a prática, a fim de, a partir de avaliações rigorosas e sistemáticas, contribuir para o avanço do conhecimento sobre os processos de ensino/aprendizagem neles envolvidos.

Ainda segundo a autora, o professor, ao assumir o papel de pesquisador em sua sala de aula através do estudo científico e sistemático, e ainda, ao correlacionar teorias e ações metodológicas transformadoras, teria a oportunidade de interferir em situações de aprendizado específicas buscando mudanças significativas nas ações didático-pedagógicas, com vistas a ampliar o aprendizado de seus estudantes.

A pesquisa desenvolvida baseou-se, ainda, em uma abordagem metodológica de natureza qualitativa por se tratar de um estudo cujo foco principal é a compreensão de um determinado grupo social ou sujeitos e não a exatidão dos dados quantitativos ou a abordagem meramente experimental ou científica.

Desta forma, pautamos nosso estudo no design da pesquisa qualitativa ao definir as etapas envolvidas na pesquisa de campo e os instrumentos de análise dos dados que subsidiaram o planejamento da proposta de intervenção, a partir de sequências didáticas aplicadas em sala de aula de Língua Portuguesa. 
Para o desenvolvimento das ações presentes na pesquisa, desenvolvemos ações didáticas sequenciais nas aulas de Língua Portuguesa, a partir do suporte de um Caderno de Atividades impresso e uma plataforma online, intitulada Portal Cibernautas (disponível no endereço eletrônico: http://portalcibernautas.wixsite.com/infograficosdigitais), ambos idealizados e desenvolvidos pela professora pesquisadora especialmente para a proposta de intervenção.

\subsection{Didatização do gênero infográfico e procedimentos}

As ações de intervenção foram planejadas a partir da adaptação do modelo de sequências didáticas (SD) apresentada por Dolz; Noverraz; Schneuwly (2004). De acordo com a definição desses autores, as SD apresentam-se como um conjunto de atividades escolares em torno de um gênero textual, oral ou escrito, organizada de maneira sistemática, levando-se em conta situações reais de leitura e escrita e apresentando as semelhanças e as diferenças entre as modalidades da língua e os gêneros. Seu modelo pode ser observado na Figura 1.

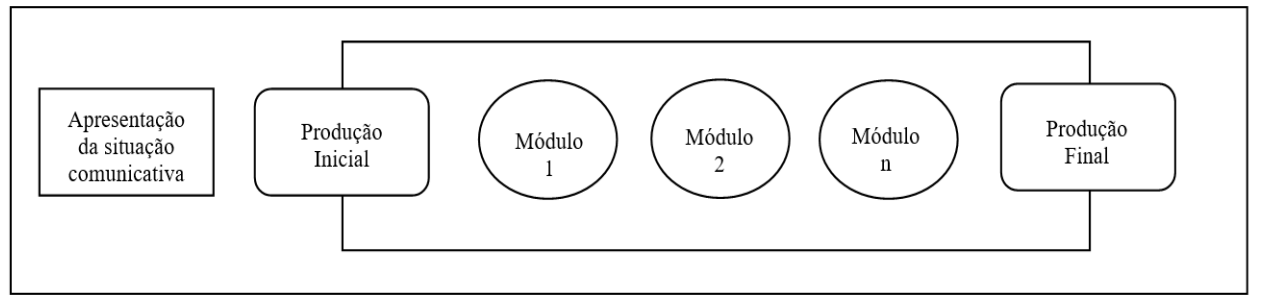

Figura 1. Esquema da sequência didática de Dolz, Noverraz e Schneuwly (2004)

Nesse modelo proposto por Dolz; Noverraz; Schneuwly (2004), as SD desenvolvem-se através da apresentação inicial da situação, onde se define a tarefa a ser desempenhada e a modalidade da língua, levando em consideração o projeto coletivo ou individual de produção do gênero, suas especificidades e os conteúdos a serem abordados; a primeira produção, a qual poderá ser desenvolvida individualmente ou coletivamente; desenvolvimento dos Módulos de Produção, seguindo passos de atividades até a produção final do gênero que deverá ser destinada à circulação real.

Outro autor propõe uma adaptação do modelo de SD apresentado por Dolz, Noverraz e Schneuwly (2004). Costa-Hübes (2009) se diferencia por apresentar um módulo de reconhecimento do gênero antes da produção inicial, como podemos observar na Figura 2. 


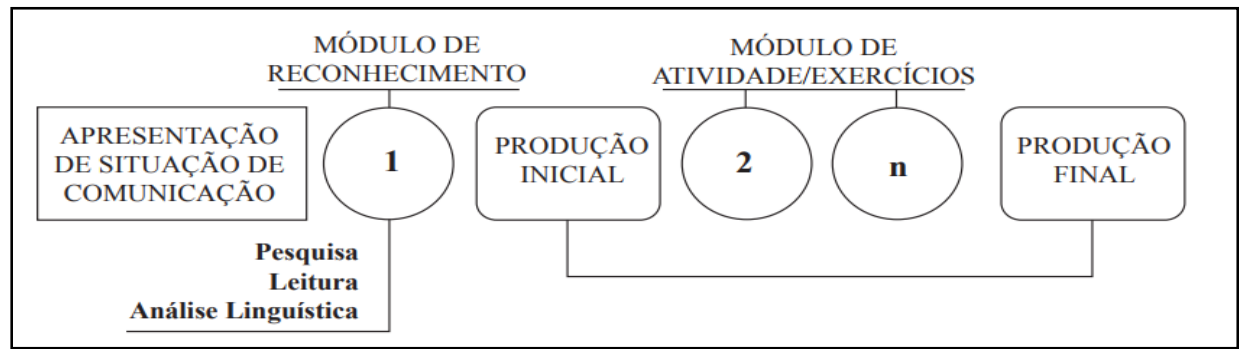

Figura 2. Esquema da Sequência Didática de Costa-Hübes (2009)

A inserção de um módulo de reconhecimento do gênero, com atividades e exercícios que contemplem a leitura de textos de circulação social já publicado na sociedade, antes da etapa da produção inicial, propicia ao estudante conhecer melhor a estrutura textual do gênero estudado e perceber as situações comunicativas que envolvem este texto.

Barreiros e Souza (2015) trazem novos elementos para esse modelo, como o Planejamento de Proposta de SD, a Sondagem, a Pesquisa de Campo e a Culminância da Intervenção, como podemos observar a partir do esquema proposto pelos autores, representado a seguir através da Figura 3.

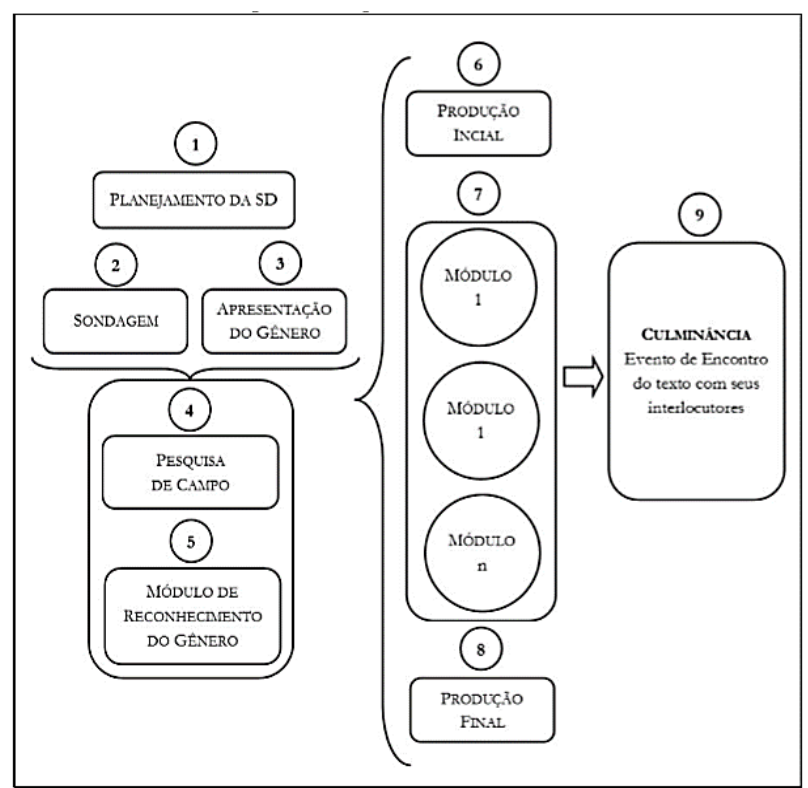

Figura 3. Esquema da Sequência Didática de Barreiros e Souza (2015)

Ao inserir a etapa de Planejamento da Proposta da SD, os autores oportunizaram a participação dos alunos neste processo de elaboração. Ao proporem a realização da Sondagem, antes mesmo da apresentação da situação de comunicação, Barreiros e Souza (2015) objetivam conhecer as situações comunicativas que os alunos vivenciam em seu cotidiano e de que maneira o gênero textual em questão encontra-se inserido em suas vidas. Por fazer parte dos objetivos e das características da 
pesquisa realizada, os autores também acrescentaram a Pesquisa de Campo e a Culminância da intervenção.

Em relação às sequências didáticas planejadas e aplicadas neste trabalho de pesquisa, elas foram elaboradas pela professora-pesquisadora a partir da adaptação dos modelos propostos principalmente pelos autores acima citados. Nela, propomos conhecer o perfil biossocial dos alunos, realizar a sondagem de seus conhecimentos prévios, a apresentação da situação comunicativa e o reconhecimento do gênero a ser trabalhado, as oficinas de design gráfico e ferramentas digitais, a produção final, os módulos de produção, a produção final, a postagem e divulgação na comunidade através da internet, a culminância e, por fim, a sistematização dos dados, como podemos observar no diagrama representado na Figura 4, a seguir.

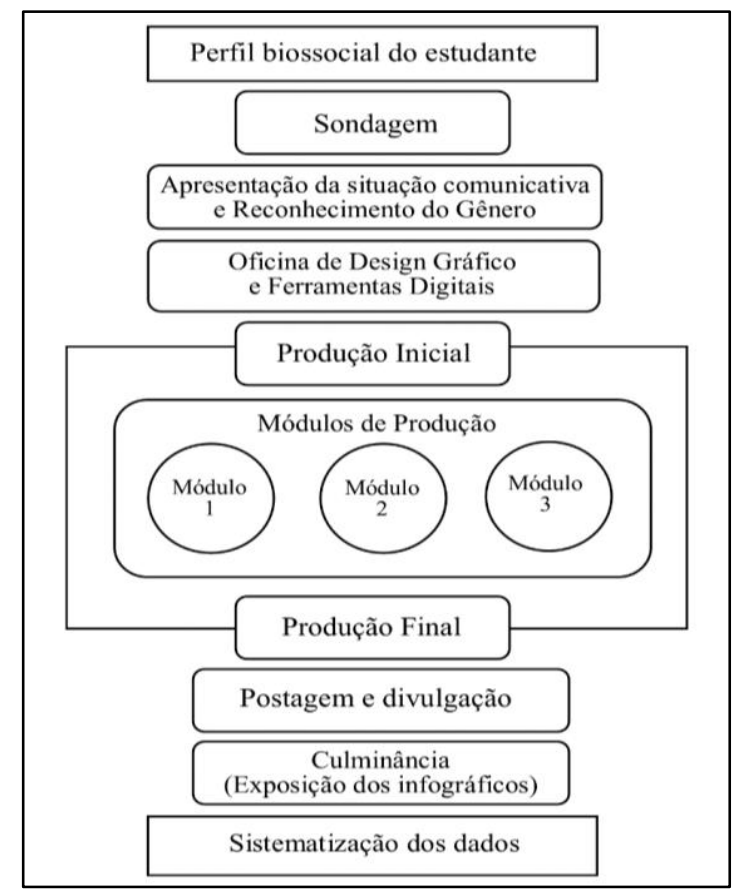

Figura 4. Esquema da Sequência Didática utilizada nesta pesquisa

Desta forma, o planejamento da nossa SD constituiu-se em um conjunto de atividades escolares em torno do gênero textual infográfico digital, organizada de maneira sistemática em dez momentos. Detalhando cada etapa da SD e seus objetivos, no primeiro momento foi aplicado um questionário misto, disponível no Caderno de Atividades, com perguntas voltadas para dados pessoais e escolares dos estudantes, bem como referente aos seus hábitos e dificuldades de leitura, escrita e uso das TDIC. O objetivo deste momento foi, além de conhecer o perfil do estudante, guiar todo planejamento e a reelaboração da SD. De fato, tanto o planejamento da SD quanto o material didático 
e plataforma online produzidas para a intervenção foram pensadas de maneira a serem flexíveis, propiciando a sua reelaboração quando e se necessário.

No segundo momento, propomos a aplicação das atividades de sondagem, onde foram desenvolvidas atividades com o apoio do Caderno de Atividades e do Portal Cibernautas, a partir de textos multimodais, com o objetivo de aferirmos o conhecimento prévio do aluno em relação ao gênero textual infográfico. A partir dos dados revelados naquela atividade tivemos elementos para elaborar as demais etapas da intervenção, levando em consideração aspectos específicos acerca do que os estudantes já sabem e seu nível de conhecimento.

Logo após, houve o terceiro momento da SD, a Situação Comunicativa e o Módulo de Reconhecimento de Gênero, onde os alunos conheceram a estrutura textual do gênero, a partir da apresentação de infográficos impressos e digitais em seus suportes de circulação social.

No quarto momento foi proposto a realização das Oficinas de Design Gráfico e Ferramentas Digitais. Nestas oficinas, foram promovidas palestras com a participação de um profissional em Design Gráfico e Infográficos, que apresentou aos estudantes algumas noções técnicas a respeito da história da infografia, além dos conceitos e exemplos de vários infográficos impressos e online. Posteriormente, os estudantes participaram de oficinas práticas sobre ferramentas digitais para construção de infográficos a partir da plataforma online e gratuita, Wix.com. Foi disponibilizada também na plataforma online uma página com vídeos tutoriais criados pela professora-pesquisadora para auxiliar os estudantes na criação dos infográficos.

As oficinas práticas foram ministradas pela professora-pesquisadora no laboratório de informática da escola e representou um importante momento de aprendizado, onde os estudantes se instrumentalizaram das ferramentas necessárias para a efetiva construção dos infográficos digitais. Só então, os alunos foram desafiados a realizarem a Produção Inicial.

No quinto momento foi apresentado o módulo da Produção Inicial, onde os estudantes produziram colaborativamente o gênero infográfico digital destinado à circulação na comunidade através de uma Revista Digital produzida pela professora-pesquisadora especialmente para a divulgação de textos produzidos pelos alunos. Os temas e as etapas de construção dos infográficos digitais foram determinados em grupo pelos próprios estudantes. Eles passaram pelas etapas de escolha do tema e dos objetivos da escrita, de pesquisa do tema na internet ou outras fontes; de desenho do rascunho do layout do infográfico; e da criação do infográfico a partir das ferramentas digitais disponíveis. Após analisarmos a produção inicial dos sujeitos e identificarmos as dificuldades de escrita apresentadas, reelaboramos o material didático dos Módulos de Produção, com o objetivo de ajuda-los a superar ou ao menos minimizar os problemas detectados na escrita inicial. 
No sexto momento, intitulado Módulos de Produção, foram desenvolvidas atividades envolvendo leitura e escrita de textos multimodais, com o apoio do Caderno de Atividades e do Portal Cibernautas. Estes módulos foram subdivididos em três etapas e abarcaram os pontos de maior dificuldade apresentados pelos sujeitos, a partir de assuntos como: (1) processos cognitivos a escrita e suas etapas de produção; (2) elementos sociocomunicativos do gênero; (3) multimodalidade e hipertextualidade. Em cada uma dessas três etapas, os estudantes revisaram as suas produções e as dos seus colegas, apontando, a partir dos elementos vistos, os possíveis problemas de escrita e sugerindo melhorias. Esta dinâmica reforçaria o trabalho colaborativo e enriqueceria as produções escritas.

Para a Produção Final, que corresponde ao sétimo momento da proposta de intervenção, os alunos foram estimulados a revisarem, reestruturarem e reescreverem suas produções textuais, realizando quantas reescritas fosse necessário, levando em consideração os pontos trabalhados nos Módulos de Produção, as observações dos colegas e da professora-pesquisadora. Ao final do processo, os alunos postaram suas produções na Revista Digital da Escola e nas redes sociais, para circulação do gênero na comunidade, o que veio a ser o oitavo momento.

Por fim, no nono momento houve a Culminância do projeto no auditório do colégio, com a presença da comunidade escolar, para exposição dos infográficos em suas versões impressa e digital, onde aconteceu uma votação popular online para premiação dos infográficos. O último momento foi reservado à sistematização dos dados registrados a partir das atividades desenvolvidas e das fichas de avaliação. Para avaliarmos as competências escritoras desenvolvidas e ampliadas pelos sujeitos, analisamos as produções iniciais e finais, com base no que fora analisado a partir das fichas de avaliação. Para protegermos as identidades dos sujeitos, os identificamos a partir de letras e números.

\section{Análise de dados}

Na pesquisa, analisamos dois infográficos produzidos colaborativamente, bem como as produções iniciais e finais de 06 (seis) sujeitos, do Tempo Juvenil 04, do turno noturno de uma escola da Rede Estadual do município de Feira de Santana. Neste artigo, apresentaremos os resultados obtidos a partir das produções inicias e finais desenvolvidas pelo sujeito E15, bem como os saberes necessários construídos a partir da produção do Infográfico 01. 


\subsection{Resultados obtidos na Produção Inicial}

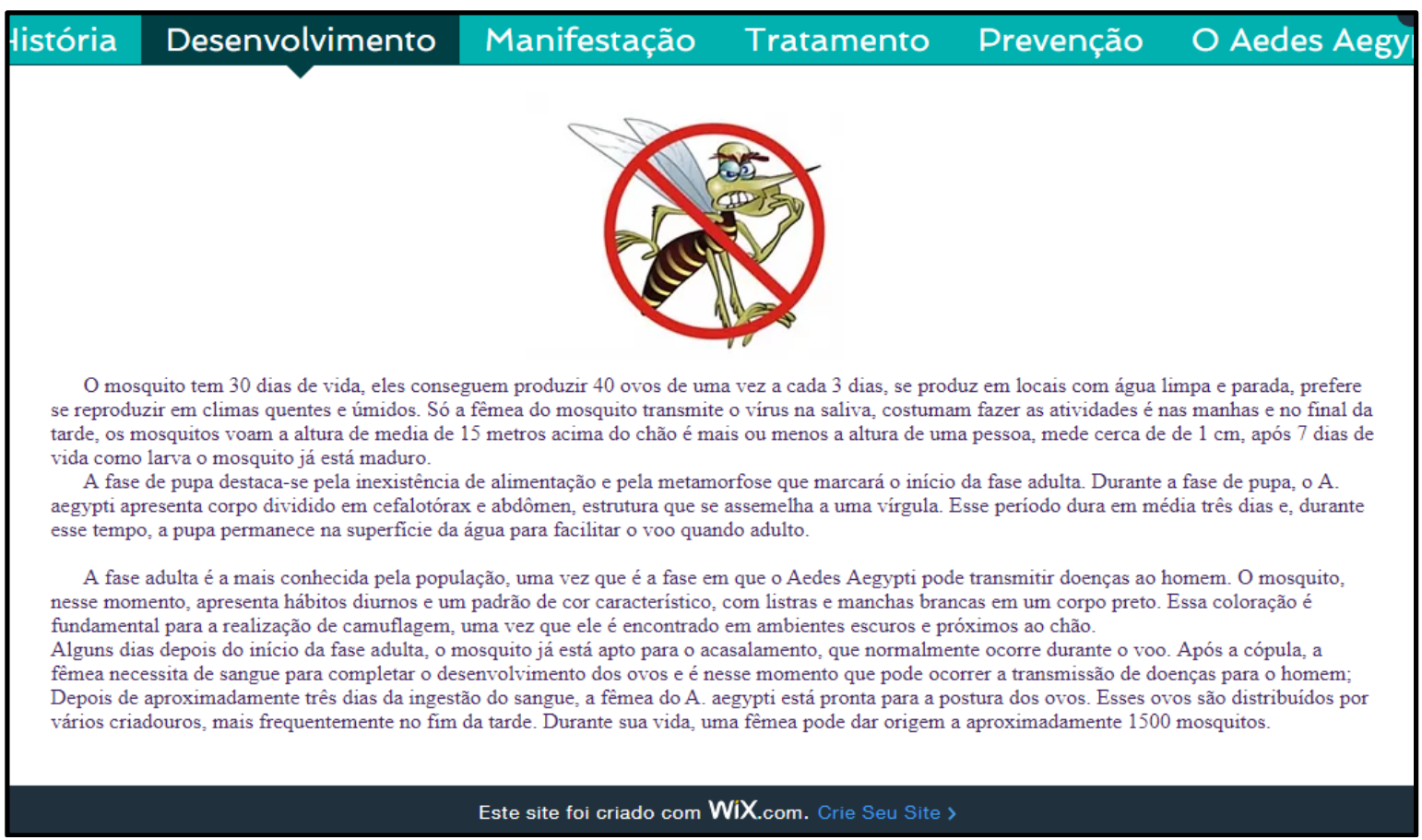

Figura 5. Infográfico 01 - versão inicial: página elaborada pelo sujeito E15

O Infográfico 01 teve como objetivo informar, por meio de um menu interativo, a respeito das características do mosquito Aedes aegypti, das principais doenças por ele transmitidas e as formas de prevenção. Em seu processo de produção inicial, o aluno E15 elaborou seu texto a partir de pesquisas realizadas na internet através de sites e blogs a respeito das fases de desenvolvimento do mosquito.

Em relação aos seus recursos visuais, percebemos que na produção inicial há a presença de uma imagem retirada da internet, sem o registro da fonte de pesquisa, que reporta à ideia de combate ao mosquito Aedes aegypti, não havendo, contudo, correlação direta com o subtópico abordado pela página, uma vez que o mesmo informa a respeito das fases de desenvolvimento do mosquito. Desta forma, a página em questão não estabelece unidade de sentido. Ora, uma vez que essa parte do infográfico trata do ciclo de vida do mosquito Aedes aegypti, o estudante E15 poderia ter selecionado e inserido elementos visuais que se relacionassem com a ideia de ciclo e de fases de desenvolvimento, o que não ocorreu.

Apesar do Infográfico em questão apresentar informações de maneira independente, ou seja, sem estar necessariamente complementando o sentido de outros textos (TEIXEIRA, 2010, p. 53), a forma de organização dos elementos multissemióticos apresentada no interior de suas páginas não foi pensada de forma a facilitar a visualização do todo, nem para a contribuição na composição de sentido (DIONísıO, 2006, p. 139). Ainda, quando observamos a organização interna das páginas que compõem

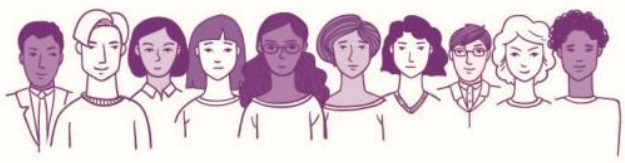


o Infográfico 01, nos deparamos unicamente com textos lineares, o que se distancia da proposta de composição hipertextual, pensada de modo a facilitar a visualização simultânea de palavras e imagens, como preconiza o gênero.

Apesar de o sujeito ter sido capaz de localizar, selecionar e resumir as informações pertinentes para o seu propósito de escrita, percebemos claramente que faltou ao seu texto, além do registro das fontes de pesquisa, elementos de coesão que permitisse uma maior conexão entre elementos e as partes do texto, de forma a manter a continuidade do assunto que se pretende desenvolver. Além disso, falta-lhe avançar para outras etapas de forma a desenvolver outras competências, como identificar as palavras-chave e as ideias de um texto, além de reagrupar essas ideias, não perdendo de vista as relações entre as unidades e realizando a reescrita com a utilização de outras palavras, indicando a(s) fonte(s) de pesquisa utilizada(s).

O salto para estas próximas etapas acontece a partir da mediação com outros sujeitos mais experientes, que, através desta interação, contribuem para o processo de construção do conhecimento. Em nossas ações de intervenção, buscamos que os sujeitos fossem oportunizados a darem estes saltos, a partir da mediação colaborativa tanto do professor quanto dos próprios pares que estejam em níveis de aprendizagens superiores, a partir de uma proposta colaborativa de ensinoaprendizagem. Estas ações foram desenvolvidas nos Módulos de Produção.

Após o desenvolvimento das etapas de reescrita nos Módulos de Produção, os alunos tiveram a oportunidade de ampliar seus conceitos relacionados ao gênero infográficos e suas características comunicativas, processos cognitivos da escrita, coerência, coesão, paráfrases, multimodalidade e hipertextualidade, a partir de textos multimodais em seus contextos reais de circulação na sociedade. A partir destas atividades de leitura, os sujeitos foram oportunizados a revisarem suas produções. 


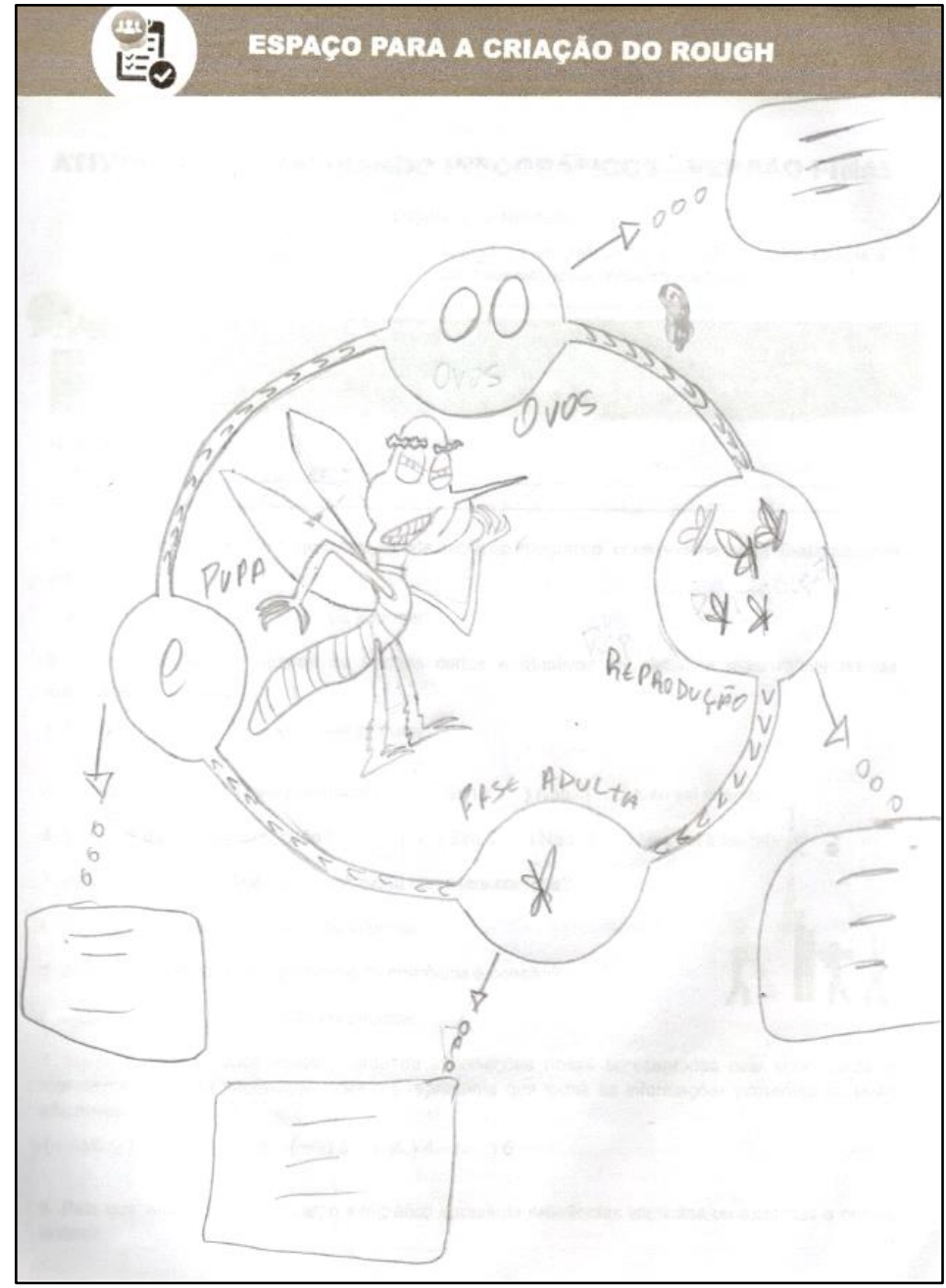

Figura 6. Infográfico 01 - versão final: rascunho elaborado pelo sujeito E15

Em seu rascunho (Figura 6), o sujeito E15 pode planejar de acréscimo de elementos multimodais e mudança na forma de apresentação das informações, antes apresentadas a partir de textos lineares, agora dispostos em janelas vinculadas a imagens organizadas em círculos, o que se harmoniza com a ideia de ciclo apresentada pela página do infográfico. Com a reorganização dos textos escritos, passando a serem apresentados a partir de janelas interativas acessíveis através de hiperlinks, houve a utilização do recurso hipertextual no intuito de facilitar a visualização e compreensão do todo.

Desta forma, em sua versão final (Figura 7), o sujeito E15 reorganizou as informações separando-as de acordo com as fases do ciclo de vida do mosquito, a saber, Ovos, Pupa, Fase adulta e Reprodução, usando este critério para criar os subtópicos abordados pela página. 


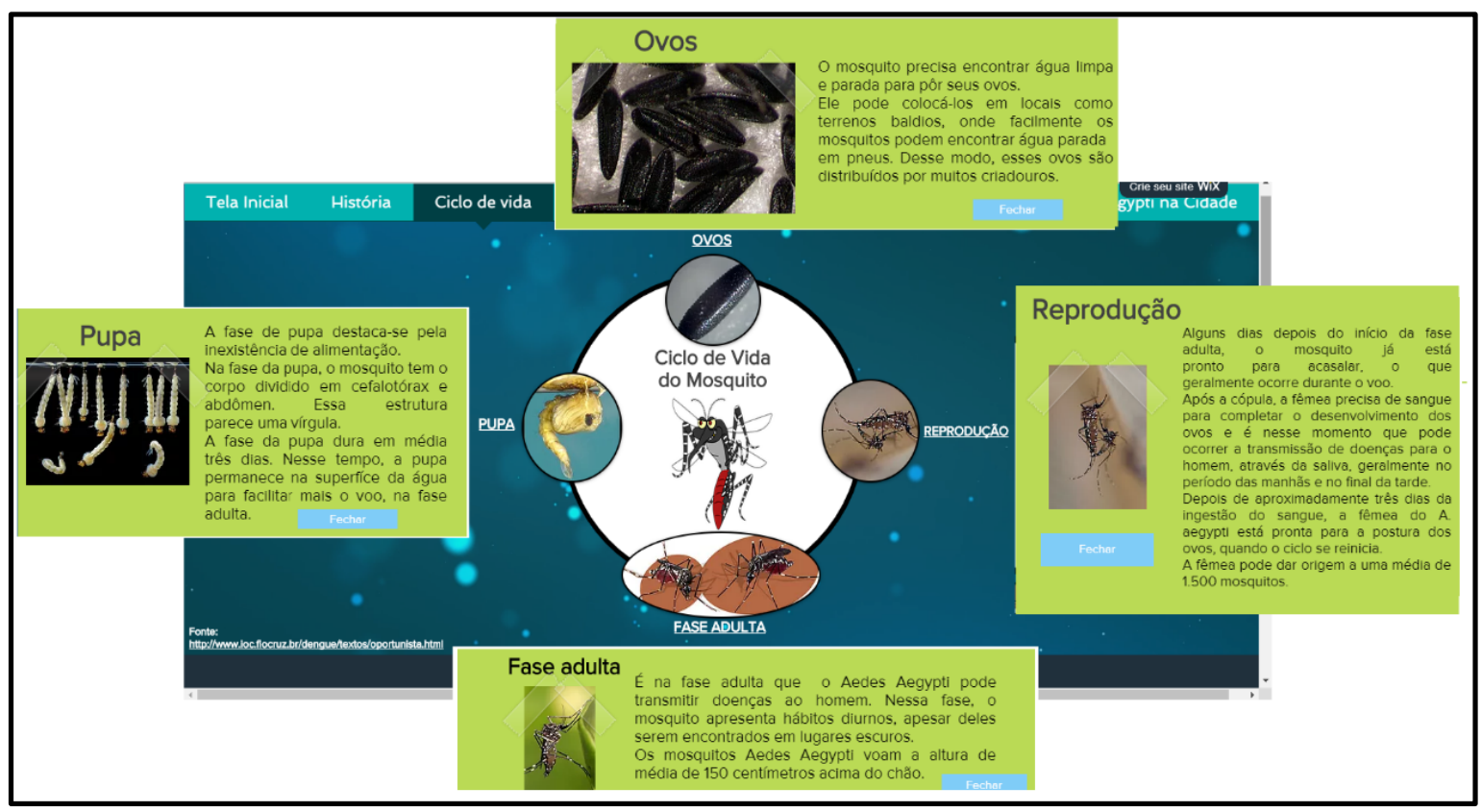

Figura 7. Infográfico 01 - versão final: página elaborada pelo sujeito E15

Desta maneira, foi possível a visualização do todo e a leitura simultânea de imagens e palavras, facilitando a construção do sentido textual e adequando a produção escrita aos parâmetros exigidos pelo gênero (DIONÍSIO, 2006, p. 139). Apesar dos pontuais desvios à norma padrão da Língua Portuguesa, o texto analisado apresenta ordenação de ideias e informações relevantes em relação ao tema proposto.

Fazendo uma análise comparativa entre os resultados obtidos nas produções iniciais e finais, avaliamos as competências desenvolvidas ou ampliadas pelos alunos, tomando por base os saberes necessários construídos dentro do que é esperado para a turma do Tempo Juvenil 04. 0 resultado desta análise busca responder a nossa questão de pesquisa, que seria: Quais saberes necessários voltados para a competência escritora podem ser construídos a partir do desenvolvimento de sequências didáticas voltadas para práticas de leitura e escrita de textos multimodais com foco na produção colaborativa de infográficos digitais nas aulas de Língua Portuguesa?

Como mostra o Quadro 1, a seguir, houve avanços nas capacidades de selecionar textos para leitura individual e coletiva (SNO2), compreender e interpretar textos lidos selecionando dados e informações (SN03), elaborar paráfrases dos textos lidos (SN01), realizar a reescrita de textos sem perder de vista as ideias originais (SN05), e organizar, com maior visibilidade, a estrutura do texto escrito em função das características do gênero (SNO4). 


\begin{tabular}{|c|c|c|c|c|c|c|}
\hline \multicolumn{7}{|c|}{ CRITÉRIOS OBSERVADOS PARA AS PRODUÇOES INICIAIS E FINAIS } \\
\hline \multirow{2}{*}{$\begin{array}{l}\text { A partir da observação dos } \\
\text { processos de produção colaborativa } \\
\text { de infográficos digitais, o estudante: }\end{array}$} & \multicolumn{2}{|c|}{ AC } & \multicolumn{2}{|c|}{ EC } & \multicolumn{2}{|c|}{ C } \\
\hline & PI & PF & PI & PF & PI & PF \\
\hline $\begin{array}{l}\text { SN01—elabora paráfrases dos textos } \\
\text { lidos }\end{array}$ & E19, E36 & & $\begin{array}{c}\mathrm{E} 02, \mathrm{E} 15, \mathrm{E} 32, \\
\text { E21 }\end{array}$ & & & \begin{tabular}{|l} 
E02, EE15, E32, \\
E19, E21, E36
\end{tabular} \\
\hline $\begin{array}{l}\text { SN02-seleciona textos para leitura } \\
\text { individual e coletiva }\end{array}$ & & & & & $\begin{array}{c}\text { E02, EE15, E32, } \\
\text { E19, E21, E36 }\end{array}$ & $\begin{array}{l}\text { E02, EE15, E32, } \\
\text { E19, E21, E36 }\end{array}$ \\
\hline $\begin{array}{l}\text { SN03-compreende e interpreta textos } \\
\text { lidos, selecionando dados e } \\
\text { informaçóes }\end{array}$ & & & & & $\begin{array}{c}\text { E02, EE15, E32, } \\
\text { E19, E21, E36 }\end{array}$ & \begin{tabular}{|l} 
E02, EE15, E32, \\
E19, E21, E36
\end{tabular} \\
\hline $\begin{array}{l}\text { SN04-organiza, com maior } \\
\text { visibilidade, a estrutura do texto escrito } \\
\text { em função das características do } \\
\text { gênero }\end{array}$ & $\mathrm{E} 02, \mathrm{E} 15, \mathrm{E} 32$ & & E19, E21, E36 & & & $\begin{array}{r}\mathrm{E} 02, \mathrm{EE} 15, \mathrm{E} 32 \\
\mathrm{E} 19, \mathrm{E} 21, \mathrm{E} 36\end{array}$ \\
\hline $\begin{array}{l}\text { SN05-realiza a reescrita de textos } \\
\text { sem perder de vista as ideias originais }\end{array}$ & $\begin{array}{l}\mathrm{E} 02, \mathrm{E} 15, \mathrm{E} 32 \\
\mathrm{E} 19, \mathrm{E} 21, \mathrm{E} 36\end{array}$ & & & & & $\begin{array}{r}\mathrm{E} 02, \mathrm{EE} 15, \mathrm{E} 32 \\
\mathrm{E} 19, \mathrm{E} 21, \mathrm{E} 36\end{array}$ \\
\hline $\begin{array}{l}\text { LEGENDA: } \\
\text { PI: Produção Inicial } \\
\text { PF: Produção Final }\end{array}$ & & & & & & \\
\hline
\end{tabular}

Quadro 1. Níveis dos saberes construídos - produções iniciais e finais

No que diz respeito à multimodalidade e a hipertextualidade, presentes nas produções finais dos sujeitos pesquisados, vemos que os alunos ampliaram suas capacidades de busca e seleção de elementos multissemióticos, ao pesquisarem novas imagens que consideraram mais relevantes para compor seus infográficos interativos. Além disso, o avanço na capacidade de uso das ferramentas digitais disponíveis na plataforma online para a organização desses elementos através de hiperlinks contribuiu para visualização simultânea de palavras e imagens e construção de sentido. Diferentemente de suas produções iniciais, os sujeitos pesquisados registraram as fontes das imagens e das informações na composição final dos infográficos interativos, demonstrando a compreensão da importância do registro das fontes que serviram como base para a produção textual.

Em relação à postura colaborativa dos alunos, pudemos observar avanço, uma vez que, a partir do processo de criação do rascunho do infográfico e da reescrita dos textos escritos, houve uma maior interação entre os sujeitos. Para chegarem à produção final, os alunos colaboraram nos processos de revisão e reescrita de seus textos, buscando evidenciar os aspectos mais importantes das informações pesquisadas e ajudando uns aos outros na superação ou, ao menos, na minimização dos problemas ligados à escrita. Essa produção coletiva do conhecimento, construída a partir da troca e da interatividade entre os alunos, contribuiu para a formação da sua autonomia no processo ensinoaprendizagem, tornando o estudante, desta forma, o agente protagonista do processo de construção do conhecimento. 
Considerações finais

$\mathrm{O}$ ato de escrever não se configura numa ação simples que estaria pronta e acabada em um intervalo curto de tempo. É, antes, um processo que demanda tempo, memória, organização, paciência, persistência e técnica. Entretanto, em sala de aula, muitas vezes essas características nos são negadas, uma vez que a própria estrutura escolar que distribui as aulas em uma carga horária restrita e fragmentada dificulta o desenvolvimento de atividades de leitura e escrita, comprometidas com os aspectos cognitivos que essas ações exigem.

O desafio que nos é imposto, tanto enquanto docente quanto pesquisador, no entanto, não deve ser visto como barreira ou impedimento, ao contrário, deve ser encarado como mote para pensarmos soluções e estratégias de superação para alcançarmos nossa meta educativa de formação de leitores e escritores mais competentes. Por isso, aceitamos o desafio de propor as ações interventivas apresentadas neste artigo. Buscamos com isso, propiciar aos alunos, práticas de leituras e escritas, além das já desenvolvidas nas práticas convencionais.

Ao desenvolvermos nossa proposta interventiva a partir de SD, percebemos que para que haja contribuições efetivas para a ampliação das competências escritoras dos alunos, é inevitável a redefinição dos papéis do professor/estudante e a mudança na concepção do processo de ensinoaprendizagem, redirecionando as ações educativas para além da mera instrução ou transmissão de conhecimento, alicerçando-se na interação, mediação e colaboração.

Quando assumimos a postura de permitir o protagonismo do aprendiz, admitimos que o aluno pode e deve ter um papel ativo no processo de construção do saber. Nessa perspectiva, a construção do conhecimento passa a ser coletiva a partir das vivências e experiências dos sujeitos. Tanto educador quanto educando possuem voz e devem contribuir com o saber, em uma perspectiva de aprendizagem colaborativa, oportunizando, desta forma, que alunos em degraus mais elevados no nível de conhecimento, possam ajudar outros colegas em degraus mais baixos a avançarem.

No ciberespaço, essa interação pode ser exercida de maneira mais evidente, por conta de suas características como fluidez, rapidez no compartilhamento de saberes e interatividade. Estes aspectos fazem com que elementos como a colaboração sejam potencializados no processo de aprendizado. Apesar de Leite et al. (2005) admitir que a aprendizagem colaborativa não dependa das TDIC para acontecer, os autores consideram que "o computador pode ser considerado como um recurso para a aprendizagem colaborativa, pois além de servir para a organização das mais diversas atividades, pode ser um meio para que os alunos colaborem uns com os outros nas atividades de grupo" (LEITE et al., 2005, p. 1121). 
De fato, em nossa pesquisa, percebemos que as TDIC tiveram um papel auxiliador no processo de interação e construção do conhecimento. Contudo, foram as experiências vividas e as interações entre os sujeitos que determinaram de que maneira esses conhecimentos foram construídos. Ora, uma vez que as informações estão ao alcance de um toque, na palma das mãos dos alunos, fica claro que as estratégias de aprendizagem devem ser outras, indo além da simples apresentação ou exposição do conhecimento.

Não devemos acreditar, entretanto, que as novas tecnologias são as salvadoras da educação, porque elas não são. E nem pretendem ser. Muito menos devemos assumir a postura de ruptura com o analógico. Indo pelo caminho contrário a isso, propomos que a escola se utilize do ambiente digital, explorando suas possibilidades de ampliação das práticas de multiletramentos, aliadas a outras fontes de leitura e escrita convencionais, dando oportunidade ao estudante de expandir seu repertório e aprender a lidar de maneira crítica com o oceano hipermidiático nos quais navegamos cotidianamente, encarando-o não apenas como fonte de informação, mas, como fora dito, como meio de comunicação, de socialização e de construção do conhecimento.

Outro fator que podemos destacar ao promovermos a participação ativa do estudante no processo de aprendizagem, diz respeito ao senso de responsabilidade e o desenvolvimento da autonomia. $\mathrm{O}$ estudante pode e deve propor atividades e sugerir os caminhos para sua execução, propor temáticas que possam ser discutidas no grupo, contribuindo com a sua visão de mundo e suas referências para a construção coletiva do conhecimento em sala de aula. Desse modo, o estudante perceberá que é efetivamente ativo no processo de aprendizado. Por esse fato, os temas a serem abordados nos infográficos foram escolhidos pelos próprios alunos, o que refletiu em um maior envolvimento em relação à busca e seleção das informações, uma vez que os assuntos pesquisados eram do interesse deles.

Assim, tendo em mente que os processos de desenvolvimento da competência escritora são amplos, buscamos, nesta pesquisa, abarcar alguns aspectos relacionados à escrita e percebemos, a partir dos dados observados neste estudo, que ao conduzirmos o estudante para práticas leitoras e escritoras de texto multimodais, como o infográfico, contribuímos com a ampliação de competências voltadas à busca e seleção de dados e informações de acordo com seus objetivos de leitura e escrita, composição de sentido ao correlacionar textos verbais e não verbais, reescrita de textos mantendo-se a ideia original através do recurso da paráfrase, escrita de textos informativos, produção de textos hipermidiáticos que apresentam temas de relevância social. Além disso, percebemos a ampliação da autonomia, colaboração, criatividade e criticidade dos sujeitos voltados aos anseios e exigências de uma sociedade tecnológica digital. 
Os caminhos traçados através desta pesquisa são, entretanto, iniciais. A partir dela, esperamos promover debates acerca do uso didático de gêneros multimodais em sala de aula de Língua Portuguesa aliado ao uso das Tecnologias Digitais de Informação e Comunicação como mote para o desenvolvimento e ampliação de competências leitoras e escritoras. Desta forma, esperamos que novas pesquisas sobre a temática possam ser realizadas, uma vez que, pelo fato, sempre existem lacunas a serem preenchidas com a realização de novos estudos e para a ampliação e obtenção de novos resultados.

Deste modo, partindo de ações de multiletramentos, a partir de uma perspectiva sociocultural voltadas para as novas necessidades do estudante, devemos oportunizar a utilização das múltiplas linguagens, proporcionando a ampliação da habilidade complexa de relacionar entre si informações verbais e não verbais encontradas em textos multissemióticos, em direção à sua emancipação intelectual. Afinal, não podemos conceber as escolas como espaços de simples transmissão de conhecimento, mas antes, precisamos (re)pensar caminhos que proporcionem ambientes para uma aprendizagem significativa, buscando oportunidades para desenvolver indivíduos autônomos, colaborativos e criativos, voltados aos anseios e exigências da sociedade em que estão inseridos e que possam trazer a estas, contribuições efetivas.

\title{
Collaborative production of multimodal texts from the genus digital infographic
}

\begin{abstract}
This article aims to present the results obtained from the research developed in the context of the intervention PROFLETRAS/UEFS. The research aimed to develop didactic-pedagogical actions focused on collaborative writing of infographics, combining the use of DICT to teaching-learning in Portuguese Language, with a view to broadening the powers of writers students of the Tempo Formativo Juvenil 04, night shift of a school in the State of the city of Feira de Santana, Bahia. Intervention research developed is entered in the field of research applied in nature, where we develop didactic sequences devoted to reading and writing practices of multi-modal texts, from the textual genre infographic, with support of an online platform, entitled Portal Internet surfers, and a schedule of Activities designed by the teacher-researcher. We realize, from data obtained in this study, advances in competence writer, autonomy, collaboration, creativity and criticality of the subject.
\end{abstract}

Keywords: Infographic. Multimodality. Hypertext. Multiliteracies.

\section{Referências}

AFONSO, C. A. Internet no Brasil: alguns dos desafios a enfrentar. Informática Pública, v. 4, n. 2, p. 169184, 2002. Disponível em: < http://www.ip.pbh.gov.br/ANO4_N2_PDF/ip0402afonso.pdf>. Acesso em: 19/05/2016.

BAHIA. SEC/DEB/CEJA. Educação de Jovens e Adultos. Tempo Formativo Juvenil. Secretaria da Educação. 2010.

BARREIROS, P. N.; DE SOUZA, W. C. Inserção da literatura local nas aulas de Língua Portuguesa: uma experiência com a literatura de Juazeiro-BA. A COR DAS LETRAS (UEFS), v. 16, p. 70-90, 2015. 
COSCARELLI, C. V. Tecnologias para aprender. São Paulo: Parábola Editorial, 2016.

COSTA-HÜBES, T. da C.; BAÜMGARTNER, C. T. (Orgs.) Sequencia didática: Uma proposta para o ensino da Língua Portuguesa no Ensino Fundamental - Anos Iniciais. Caderno pedagógico 3: AMOP. Cascavel: Assoeste, 2009.

COSTA, S. R. Dicionário de gêneros textuais. Belo horizonte: Autêntica Editora, 2014.

DAMIANI, M. F. Sobre pesquisas do tipo intervenção. In: XVI ENCONTRO NACIONAL DE DIDÁTICA E PRÁTICA DE ENSINO. Anais... Campinas: UNICAMP, 2012. Disponível em: < http://www.infoteca.inf.br/endipe/smarty/templates/arquivos_template/upload_arquivos/acervo/d ocs/2345b.pdf>. Acesso em: 10 de dez. 2016.

DIONÍSIO, A. P. Multimodalidade discursiva na atividade oral e escrita (atividades). In: MARCUSCHI, L. A.; DIONISIO, A. P. (orgs.). Fala e Escrita. Belo Horizonte: Autêntica, 2006.

DOLZ, J.; NOVERRAZ, M.; SCHNEUWLY, B. Sequências didáticas para o oral e a escrita: apresentação de um procedimento. In: DOLZ, J.; SCHNEUWLY, B. e colaboradores. Gêneros orais e escritos na escola. Trad. E Org. de Roxane Rojo e Glaís Sales Cordeiro. Campinas, SP: Mercado das Letras, 2004.

LEITE, C. L. K. et al. A aprendizagem colaborativa no ensino virtual. In: V EDUCERE - III CONGRESSO NACIONAL DA ÁREA DE EDUCAÇÃO. Anais... Curitiba, 2005. Disponível em: < http://www.pucpr.br/eventos/educere/educere2005/anaisEvento/documentos/com/TCCI167.pdf>. Acesso em: 30 de dez. 2016.

LEVY, P. Cibercultura. São Paulo, 1999.

PRETTO, N.; PINTO, C. Tecnologias e novas educações. Revista Brasileira de Educação. v. 11, n. 31, jan./abr. 2006.

RIBEIRO, A. E. Textos multimodais: leitura e produção. São Paulo: Parábola Editorial, 2016.

ROJO, R.; MOURA, E. (orgs.) Multiletramentos na escola. São Paulo: Parábola Editorial, 2012.

TEIXEIRA, T. Infografia e Jornalismo: Conceitos, análises e perspectivas. Salvador: EDUFBA, 2010.

TRIPP, D. Pesquisa-ação: uma introdução metodológica. Educação \& Pesquisa, São Paulo, v. 31, n. 3, p. 443-466, 2005.

XAVIER, A. C. As tecnologias e a aprendizagem (re)construcionista no século XXI. Hipertextus Revista Digital, Recife, v. 1, 2007. In: <http://www.hipertextus.net/volume1/artigo-xavier.pdf>. Acesso em 16 de abril de 2016. 